\title{
Corpo, cidade e política na poética do coletivo Opavivará!
}

\section{Body, city and politics in the poetics of Opavivará! Ensemble}

Pedro Caetano Eboli Nogueira ${ }^{1}$ 


\section{Resumo}

Este artigo se destina a pensar possíveis entrelaçamentos entre política, corpo e cidade, no âmbito da poética do coletivo carioca Opavivará!. Inicialmente apresentamos algumas relações entre os poderes que atuam na conformação do espaço urbano e produção de subjetividades, explicitando de que forma a experiência urbana contemporânea dificulta os processos de singularização. Em seguida pontuamos de que maneira os coletivos podem assumir os vultos de importantes sujeitos políticos no contemporâneo, para então analisarmos alguns trabalhos do coletivo supracitado.

Palavras-chave: Política da estética, coletivos, corpo, Opavivará!

\section{Abstract}

This paper aims to think possible interweaving between politics, body and city, inside the poetics of the Opavivará! ensemble, based in the city of Rio de Janeiro. Firstly we present some relations between the powers that conforms the urban space and the production of subjectivities, explaining how contemporary urban experience hinders processes of singularization. Then we point out how ensembles can be important political subjects contemporarly. At the end we analyze some of the mentioned above ensemble's pieces.

Keywords: Politics of aesthetics, ensembles, body, Opavivará! 


\section{Introdução}

Este artigo se destina a pensar algumas das formas políticas possíveis da arte no âmbito das cidades contemporâneas. Para tal, inicialmente conceituamos alguns dos modos pelos quais a conformação das cidades incide sobre produção de subjetividades, de acordo com os poderes disciplinar e biopolítico, tal como enunciados pelo filósofo Michel Foucault (1989). Em complementaridade ao pensamento de Félix Guattari (1992) e Walter Benjamin (1991, 2000), procuramos mostrar que onde a figura da população toma corpo, com seus vultos fundamentalmente massificantes, parece inibir-se a permeabilidade dos processos de singularização no seio da urbanidade. A contrapelo desta tendência, situamos a tipologia dos coletivos como uma nova cartografia da grupalidade e das possibilidades de autoria que emergem no contemporâneo, estreitamente ligada à vocação política da arte no âmbito daquilo que o filósofo Jacques Rancière (2009) compreende como regime estético.

Sem o intuito de esgotar todas as possibilidades de interpretação dos fatos artísticos apresentados, seguimos analisando alguns dos trabalhos do Opavivará!, coletivo atuante especialmente na cidade do Rio de Janeiro. Com uma composição que variou tremendamente desde então, ele foi formado no ano de 2005, época em que houve uma grande proliferação dos coletivos de arte no Brasil (REZENDE \& SCOVINO, 2010), organizados e correlacionados em dinâmicas de rede. A produção artística do coletivo flutua entre a performance, o happening e a intervenção urbana, e pode ser avizinhada daquilo que o crítico francês Nicolas Bourriaud (2009) denomina Estética Relacional, uma vez que está vinculada à produção de laços sociais.

Nestas análises privilegiamos as produções em que a alimentação e os rituais ensejem formas de sociabilidade e coletividade que dialogam com tecido urbano, ainda que alguns se situem fora de espaços propriamente públicos. Assim, tencionamos justamente desenhar as relações em que a arte, em diálogo como corpo e a cidade, engendra múltiplos processos de subjetivação e constitui uma importante máquina micropolítica. Sua potência está em abrir espaço para que processos de singularização participem da experiência urbana, e é neste agenciamento que se esconde a força estético-política dos trabalhos de arte em contato com a cidade.

Nesta prática de escrita nos surgem algumas inquietações: como escapar do modelo acadêmico esterilizante, em que a mera identificação entre uma realidade dada e a teoria se justifica por si só? Ou do ímpeto de recobrir e adaptar discursivamente os trabalhos a uma teoria pré-existente, aplicando a teoria como voz de autoridade a partir da qual podemos falar o mundo? Neste sentido, procuramos exercitar a recusa de uma oposição entre poesia e argumentação, real e ficcional, tal como proposto por Jacques Rancière $(1996,2009)$, deslocando um pouco a famosa asserção de Barthes (2013) sobre a literatura como "próprio fulgor do real" (p. 19). De que forma é possível pensar a poética dos trabalhos dos sob este prisma? Talvez seja necessário entrar em contato com aquilo que Barthes localiza na literatura: "o saber que ela mobiliza nunca é inteiro nem derradeiro, a literatura não diz que sabe sobre alguma coisa, mas que sabe de alguma coisa, ou melhor, que ela sabe algo das coisas" (BARTHES, 2013, p. 19). 
É justamente a pergunta sobre este "algo", que Barthes explora na literatura, que nos move na análise destes trabalhos. Eles funcionam como pontos de partida, onde fazemos ecoar questões que fogem ao universo ficcional e dizem respeito a questões de cunho eminentemente social, intercambiando e arejando estes papéis geralmente estanques. Sob esta mesma chave de leitura procuramos interpretar e situar algumas das contradições e possíveis objeções a certos trabalhos do coletivo Opavivará!.

Explicitamos suas relações com processos de gentrificação ${ }^{1}$, inerentes ao meio da arte e alheias ao controle do coletivo, mas que não deixam de incidir sobre suas poéticas. Ao final abordamos criticamente a incorporação de dimensões alteritárias em alguns de seus trabalhos, sem o intuito de chegar a um julgamento final sobre a questão, mas abrindo espaço para que uma discussão possa ter lugar. Assim, tomamos a tarefa política do dissenso, apresentando uma breve multiplicidade de devires que atravessam simultaneamente a poética do coletivo em questão.

\title{
2.Desenvolvimento
}

\subsection{A cidade e os poderes}

Para compreendermos de que maneiras a arte pode suscitar processos de singularização no âmbito das cidades, antes observemos de que forma o planejamento urbano é tributário de um conjunto de lógicas que ao mesmo tempo opera uma massificação e individualização dos sujeitos. É justamente sobre a vida que a biopolítica, tecnologia de poder que se instala de forma maciça a partir do século XIX, se precipita e opera. Esta forma de governamentalidade se apoia sobre um aparato científico, que passa a produzir discursos verdadeiros e a incidir sobre as vidas da população. As imbricações poder-saber, sempre evidenciados nas analíticas foucaultianas, aparecem aqui de forma bastante manifesta:

\begin{abstract}
Não é exatamente com a sociedade que se lida nessa nova tecnologia de poder (ou, enfim, com o corpo social tal como o definem os juristas); não é tampouco com o indivíduo-corpo. É um novo corpo: corpo múltiplo, corpo com inúmeras cabeças, se não infinito pelo menos necessariamente numerável. E a noção de "população". A biopolítica lida com a população, e a população como problema político, como problema a um só tempo cientifico e político, como problema biológico e como problema de poder (...) (FOUCAULT, 1999, pp. 292, 293).
\end{abstract}

Esta nova tecnologia de poder se encarrega especialmente da vida, mas não naquilo que tange ao corpo individual, objeto do poder disciplinar ${ }^{2}$ por excelência. Michel Foucault (2009) compreende a individualização e a completa visibilidade como importantes elementos da lógica constitutiva de uma forma de poder que emerge no século XVII sob a forma das sociedades disciplinares. Trata-se de um poder que

\footnotetext{
1 Segundo Bidou-Zachariasen (2006) este termo foi empregado pela primeira vez na década de 1960 por Ruth Glass, que caracterizou o fenômeno como "a transformação da composição social dos residentes de certos bairros centrais, por meio da substituição de camadas populares por camadas médias assalariadas; e de um processo de natureza diferente: o de investimento, reabilitação e apropriação, por estas camadas sociais, de um estoque de moradias e de bairros operários ou populares" (p. 22). Pesquisas mais recentes realizadas em diversas cidades do mundo em volta deste tema destacam "os mesmos tipos de fatores que representam as práticas 'espontâneas' dos habitantes, seus instrumentos técnicos (financiamentos, empréstimos imobiliários, etc.) e as políticas 'voluntaristas' das administrações locais" (p. 29).

2 Nos contentemos com uma definição rápida, por hora. Para Michel Foucault (1989) o poder disciplinar surge por volta do século XVII, portanto antes do biopolítico. Enquanto este se dirige à vida, aquele está endereçado individualmente aos corpos, interessado em torná-los dóceis e produtivos. Estas duas formas de poder não se substituem historicamente, elas coexistem e se complementam. Apenas operam em diferentes níveis da sociedade.
} 
se materializa espacialmente em hospitais, escolas, oficinas e prisões, impondo moralidades sem a força de uma repressão recorrente, mas através da economia de um olhar automático e incessante.

O poder biopolítico, por sua vez, se endereça a um conjunto de homens na medida em que ele forma uma massa global, olhando para fenômenos relativos especificamente à vida, tais como nascimentos, a morte, a reprodução, a doença etc. Essa multiplicidade é encarnada na figura da população, que passa a existir neste momento, sujeitada às mais diversas quantificações estatísticas. Todavia, estes números não se restringem a uma coleta de dados, mas são usados para estipular normas, medidas e estratégias, ajudam a enformar a realidade da qual são extraídos:

Nos mecanismos implantados pela biopolítica, vai se tratar sobretudo, é claro, de previsões, de estimativas estatísticas, de medições globais; vai se tratar, igualmente, não de modificar tal fenômeno em especial, não tanto tal indivíduo, na medida em que ele é indivíduo, mas, essencialmente, de intervir no nível daquilo que são as determinações desses fenômenos gerais, desses fenômenos no que eles têm de global. Vai ser preciso modificar, baixar a morbidade; vai ser preciso encompridar a vida; vai ser preciso estimular a natalidade. E trata-se sobretudo de estabelecer mecanismos reguladores que, nessa população global com seu campo aleatório, vão poder fixar um equilíbrio, manter uma média, estabelecer uma espécie de homeostase, assegurar compensações; em suma, de instalar mecanismos de previdência em torno desse aleatório que é inerente a uma população de seres vivos, de otimizar, se vocês preferirem, um estado de vida (FOUCAULT, 1999, pp. 293, 294).

Mas o poder biopolítico também depende da assunção dos fenômenos relativos a população como naturais, de modo a recortar os seres-humanos como entidades biológicas, cujos meios podem ser modificados para garantir uma otimização da vida. Aqui surgem a medicina social e a noção de higiene pública, que fundariam as bases para a gênese do urbanismo enquanto disciplina técnica. É neste exato período histórico que o poder inicia sua gradual precipitação sobre as vidas, de modo a otimizá-las. As "ciências parcelares" operam justamente esta mecânica de uma produção incessante discursiva de verdades, quantificações estatísticas referentes à população e aos territórios.

Neste momento os homens passam a significar entidades biológicas, e as preocupações com o "meio" emergem de forma bastante acentuada. O nascimento da medicina social, no século XVIII, se dá neste bojo e passa a constituir, para Foucault, um importante tentáculo do poder biopolítico:

A localização dos diferentes bairros, sua umidade, sua exposição, o arejamento total da cidade, seu sistema de esgotos e de evacuação de águas utilizadas, a localização dos cemitérios e dos matadouros, a densidade da população constituem fatores que desempenham um papel decisivo na mortalidade e morbidade dos habitantes. A cidade com suas principais variáveis espaciais aparece como um objeto a medicalizar. Enquanto que as topografias médicas das regiões analisam os dados climáticos ou fatos geológicos que não controlam e só podem sugerir medidas de proteção ou de compensação, as topografias das cidades delineiam, pelo menos negativamente, os princípios gerais de um urbanismo sistemático. A cidade patogênica deu lugar, no século XVIII, a toda uma mitologia e a pânicos bem reais (o Cemitério dos Inocentes, em Paris, foi um destes lugares bem saturados de medo); ela exigiu, em todo caso, um discurso médico sobre a morbidade 
urbana e uma vigilância médica de todo um conjunto de disposições, de construções e de instituições (FOUCAULT, 1989, p. 201).

Todos estes espectros do medo plantados pelo discurso higienista rondaram o imaginário social da Paris do século XVIII e dariam sustentação para as reformas urbanas do século seguinte. O controle sobre a cidade, enquanto meio onde a vida deve se proliferar e ser produtiva, se torna um importante mecanismo de controle biopolítico, complementado pela lógica disciplinar de acesso ao corpo. Não por acaso as reformas urbanas realizadas entre os séculos XIX e XX, sob a inspiração da Paris de Haussmann, despertaram uma série de revoltas contra os esforços de higienização das capitais. Tratavam-se de tentativas de resistência à moralização dos corpos e controle sobre a vida impostos por estas ações, cuja violência também estava em fazer tábula rasa das memórias coletivas que se tinha dos locais. Em todo caso, a experiência da cidade está atravessada pelos poderes biopolítico, que massifica, e o disciplinar, que individualiza.

Desta forma, sob a égide do poder biopolítico vemos frágeis as possibilidades de emergência liminar de singularidades. Este poder se encarrega justamente de transformar a multiplicidade de indivíduos no corpo indiscernível da população, ele forma e faz performar as políticas de identidade e identificação. E podemos tomar as cidades como palcos desta massificação por excelência.

\subsection{Arte, corpo e cidade: processos de singularização}

O filósofo Walter Benjamin (1991) delineia a maneira como a experiência urbana age subjetivamente sobre os corpos dos indivíduos em meio à multidão. A Modernidade inaugura a possibilidade de um sujeito que se invisibiliza na massa compacta dos passantes, sem identidade, o paroxismo de uma solidão coabitada por muitos outros: "(...) por um lado o homem se sente olhado por tudo e por todos, simplesmente o suspeito, por outro, o totalmente insondável, o escondido. Provavelmente é essa dialética que o homem da multidão desenvolve" (BENJAMIN, 1991, p. 190). Se a massa "apaga todos os vestígios do indivíduo" (p. 49), o flâneur seria justamente a personagem que usa destes jogos de visibilidade, e se produz como sujeito ativo em meio à circulação frenética.

Ele se deixa circular e observa, constrói sentidos na desordem citadina, é a emergência da singularidade como abertura de potência na experiência urbana. Mas o flâneur não se constitui como uma identidade ou modo de subjetividade fixa, é um estado volátil do ser, corpo nômade, que se apresenta por um instante liminar, para logo depois ser novamente tragado pela massa confusa:

Se por um lado ele [Baudelaire] sucumbe à violência com que a multidão o atrai para si e o converte, como flâneur, em um dos seus, por outro, a consciência do caráter desumano da massa jamais o abandona. Baudelaire se torna cúmplice da multidão e quase imediatamente afasta-se dela. Mistura-se profundamente com ela, para fulminá-la, de repente, convertendo-a em nada, com um olhar de desespero (BENJAMIN, 2000, p. 49). 
Mas ao contrário da figura compacta da massa, a multidão benjaminiana seria uma coleção de individualidades que escapam dos mecanismos indentitários de captura, são "livres de determinação de classe",

apresentam-se como determinações concretas, mas socialmente permanecem abstratas (...). Muitas vezes, essas aglomerações possuem apenas existência estatística. Ocultam aquilo que perfaz sua real monstruosidade, ou seja, a massificação dos indivíduos por meio do acaso de seus interesses privados (BENJAMIN, 1991, p. 58).

Aqui podemos observar os postulados seminais de Benjamin à luz dos paradigmas biopolíticos, encetado muito posteriormente pelas analíticas foucaultianas. Deste modo torna-se possível compreender o fenômeno de massificação, em sua dependência da estatística e das políticas de identidade. Mas também estavam contidas em Benjamin (2000) formulações que deixam entrever alguns dos poderes disciplinares prementes na experiência urbana moderna. Isto pode ser notado em sua insistência em pontuar as imbricações entre os imperativos de individuação, a proliferação dos olhares e a gênese de determinados modos subjetivos e formas de moralidade.

Félix Guattari (1992) compreende justamente a impermeabilidade dos processos de singularização na experiência urbana contemporânea. Para ele há uma relação de transversalidade que rege a produção das cidades e das subjetividades. Tendo em mente que os processos de subjetivação são múltiplos e polifônicos, as urbes podem ser entendidas como enormes máquinas produtoras de subjetividade individual e coletiva, mas que também são produzidas a partir de determinadas subjetividades. O espaço construído seria uma máquina enunciadora que nos interpela a partir de diferentes pontos de vista: estilístico, histórico, funcional, afetivo:

Tudo se reduz sempre a essa questão dos focos de enunciação parcial, da heterogênese dos componentes e dos processos de re-singularização. É para essa direção que deveriam se voltar os arquitetos hoje. Eles devem assumir uma posição, se engajar (como se dizia no tempo de Jean-Paul Sartre) quanto ao gênero de subjetividade que ajudam a engendrar. Irão no sentido de uma produção reforçada de uma subjetividade do "equivaler generalizado", de uma subjetividade padronizada que tira o seu valor de sua cotação no mercado dos mass-media, ou colocar-se-ão na contracorrente, contribuindo para uma reapropriação da subjetividade pelos grupos-sujeitos, preocupados com a re-singularização e a heterogênese? Irão no sentido do consenso infantilizador ou de um dissenso criador? Mas pode-se imaginar uma pedagogia da singularidade? Não há aqui contradição nos termos? Sem dúvida existe uma potência de exemplo da diferença (GUATTARI, 1992, pp. 162, 163).

Guattari também refuta por completo a crença modernista no Universal, que funcionaria como uma máquina esmagadora e uniformizadora de subjetividades. Para ele, os arquitetos e urbanistas deveriam se tornar artistas polissêmicos e polifônicos, realizando "projetos individuais e coletivos que evoluem cada vez mais rápido e cuja singularidade - inclusive estética - deve ser atualizada através de uma verdadeira maiêutica" (GUATTARI, 1992, pp. 176, 177). Outros pressupostos de projeto podem trabalhar no sentido de uma re-singularização liberadora da subjetividade individual e coletiva, caso o planejamento das cidades seja concebido de modo a deixar lacunas que as tornem permeáveis e passíveis de apropriação pelos sujeitos. 
Trata-se, em suma, de uma transferência de singularidade do artista criador de um espaço para a subjetividade coletiva. Assim o arquiteto e o urbanista se encontram imprensados, de um lado, entre o nomadismo caótico da urbanização descontrolada ou unicamente regulada por instâncias tecnocráticas e, por outro lado entre seu próprio nomadismo mental se manifestando através de sua projetualidade diagramática. Essa interação entre a criatividade individual e as múltiplas coações materiais e sociais conhece, entretanto, uma sanção de veracidade: existe, de fato, uma transposição de limiar a partir da qual o objeto arquitetural e o objeto urbanístico adquiram sua própria consistência de enunciador subjetivo (GUATTARI, 1992, p. 178).

Os espaços construídos possuiriam, portanto, um alcance que transcende à funcionalidade e às estruturas visíveis. Eles seriam máquinas produtoras de sentido, que, apesar de não serem Universais, "podem tanto trabalhar no sentido de um esmagamento uniformizador quanto no de uma re-singularização liberadora da subjetividade individual e coletiva" (idem, p. 158).

Posto isso, como imaginar politicamente o corpo em uma cidade, de modo a deixar em aberto as potências de singularização? Compreendemos que as intervenções urbanas, ao contrário de objetivarem a solução de problemas da cidade, partem de uma outra lógica de pensamento, propondo-lhe questões. A inquietude liminar que move um questionamento, impassível de ser assentado ou fechado completamente, mas que o mantém suspenso, significa autorizar uma multiplicidade multitudinária e dissensual de possíveis interpretações. Neste campo aberto pode emergir um sujeito que não se vê rendido aos limites de uma intersubjetividade pedagógica: cabe a ele a construção de sentidos. Mas é também neste mesmo sujeito que o fato artístico atua no debandar das identidades e no descolamento de tudo aquilo que lhe faz uno e indivisível de si mesmo.

Para Jacques Rancière (2009), a experiência sensível não é jamais um dado imutável ou natural, mas uma partilha em disputa, atravessada por uma série de vetores eminentemente históricos e sociais. O autor compreende que a organização desta partilha do sensível é realizada pela figura que ele denomina por polícia, uma espécie de dispositivo cultural que gere os corpos e vidas em sociedade, de modo a garantir a continuidade e repetição das condições que estão dadas na organização da polis. $A$ política, por outro lado, estaria ligada ao exercício do dissenso, ou seja, de qualquer atividade que modifique aquilo que é visível, dizível e contável, de modo a perturbar a ordem imposta pela polícia. Daí podemos extrair algumas das imbricações entre cidade, corpo e política.

O dissenso, por sua vez, seria aquilo que une definitivamente a política aos trabalhos de arte produzidos sob a égide do regime de identificação que Rancière denomina como estético, ou seja, aqueles presididos por um conjunto de lógicas de criação e recepção que tomaram corpo especialmente a partir dos modos de subjetividade da Era Democrática. Ao imbricar a apreensão dos sentidos a uma possibilidade infinita de atribuição de sentidos, estes trabalhos artísticos potencialmente colocam o espectador em uma posição ativa em sua produção enquanto sujeito e podem engendrar modos de subjetivação semelhantes àqueles que o mesmo filósofo advoga como condição para a política. Assim, cabe a esta forma política não uma afronta ao Estado, mas a produção de pequenas fissuras na ordem do sensível. Elas deslocam os sujeitos de sua identidade e daquilo que os fixa a si próprios, abrindo potência para a 
emergência contingencial de singularidades em meio a uma urbanidade que incessantemente massifica e individualiza os sujeitos.

\subsection{Os coletivos}

Deste modo, as formas de incidência do poder sobre os sujeitos contemporâneos parecem ensejar questionamentos substanciais quanto à autoria e as tipologias de grupalidade no âmbito da arte. Não por acaso tenhamos visto a proliferação crescente de coletivos de arte e de ativismo político. Trata-se de uma reunião de múltiplos sujeitos em que são mantidas suas singularidades, como aponta Cezar Migliorin (2012):

um coletivo é antes um centro de convergência de pessoas e práticas, mas também de trocas e mutações, (...) um coletivo não faz unidade, mas é formado por irradiação dessa intensidade, um condensador, agregador de sujeitos e ideias, em constantes aproximações, distanciamentos, adesões e desgarramentos (p. 308).

Em contraponto à ideia do gênio artístico criador, esta formação possibilita que a identidade do grupo seja pulverizada. Ela também se difere de experiências modernas em que manifestos impunham uma lei geral para os artistas de um determinado movimento ou grupo. Ao contrário da vontade de unidade, a busca do coletivo é a de se manter em constante tensão dissensual.

Podemos traçar uma analogia ao corpo multitudinário de Hardt e Negri (2005): cada integrante mantém sua individualidade e é livre para falar em nome do grupo. Embora spinozistas 3 , Michael Hardt e Antonio Negri, ao conceberem a figura da multidão, parecem atualizar as formulações benjaminianas à luz da biopolítica e das concepções contemporâneas de subjetividade. Os filósofos imaginam um corpo social que não se limita à massa indistinta da população, mas que articula uma "nova relação entre o que é comum e o que é singular" (HARDT \& NEGRI, 2005, p. 253), sendo a multidão justamente composta de um "conjunto de singularidades" (p. 139). Aqui a diferença do sujeito social não pode ser reduzida à uniformidade, mas é "uma diferença que se mantém diferente" (idem). Ao mesmo tempo, cada indivíduo é também uma potência multitudinária em si mesmo, atravessado por múltiplos devires e subjetividades. Todavia,

um fato que deve ficar claro em tudo isso que é a multidão não surge espontaneamente como forma política, e que a carne da multidão consiste numa série de condições que são ambivalentes: poderiam levar à libertação ou ser apanhadas num novo regime de exploração e controle (HARDT \& NEGRI, 2005, p. 275).

Este paradigma estabelece uma relação paradoxal e irresoluta entre unidade e fragmentação, que fomenta um nomadismo ideológico radical. Se para Rancière (1996) a política teria justamente a ver com modos de subjetivação, então talvez a formação deste corpo coletivo composto por múltiplas singularidades seja relevante, uma vez que "a diferença que a desordem política vem inscrever na ordem policial pode portanto, em primeira análise, exprimir-se como diferença entre uma subjeti-

3 O filósofo holandês Baruch Espinoza (1632-1677) trabalhou extensamente sobre o tema da multidão, basilar para sua teoria política. O conceito encontrou pouquíssimos ecos em seu tempo, mas há toda uma linhagem contemporânea da filosofia, a começar por Nietzsche, que resgatou algumas das teorias spinozistas. 
vação e uma identificação" (p. 49). Neste sentido, a reunião enquanto coletivo pode significar uma outra "cartografia da grupalidade" (PÉLBART, 2008) que, idealmente, encarnaria alguns importantes elementos do sujeito político no contemporâneo, similar à grupalidade do bando (BEY, 2004). Se o poder se exerce a partir de vetores ao mesmo tempo individualizantes e totalizadores (FOUCAULT, 1995), talvez se trate de criar uma outra corporeidade coletiva que não seja redutível à soma de suas partes.

Um pensamento similar parece ter norteadoo antropólogo Victor Turner (2008) ao formular aquilo que ele denomina como experiências de communitas. Nela o fator que une as pessoas é eminentemente circunstancial, escapando das coesões sociais e mecanismos de identidade:

Aqui, "conflito" é o outro lado da moeda da "coesão", sendo "interesse" o motivo que vincula ou separa estas pessoas, estes homens servis a direitos estruturais e obrigações, imperativos e lealdades. (...) os laços de communitas são antiestruturais, uma vez que são indiferenciados, igualitários, diretos, não-racionais (embora não irracionais), relações Eu Tu ou Nós Essencial, no sentido de Martin Buber. Estrutura é o que mantém as pessoas separadas, define suas diferenças e limita suas ações, incluindo a estrutura social no sentido da antropologia britânica. A communitas fica mais clara na "liminaridade" (TURNER, 2008, p. 41).

Ora, para o antropólogo, as experiências de communitas estão ligadas à crise, a fase liminar daquilo que ele caracteriza como drama social ${ }^{4}$. Nela torna-se possível produzir fraturas nas estruturas. Esta etapa do drama social assiste a abertura de potências, que dependem de uma suspensão irresoluta. Deste modo, então talvez haja algo de subversivo que as atravessa, pois justamente nesta fase de suspensão são estabelecidos liames afetivos que não se deixam facilmente cartografar.

Neste sentido, o coletivo se constitui como uma formação que funciona como uma espécie de Navio de Teseu: ela pode assistir a uma reposição total de suas partes exclusivas e ainda assim existir, pois há uma espécie de bússola incerta que guia sua produção artística. Aqui podemos estabelecer uma analogia com a fantasia da idiorritmia proposta por Roland Barthes (2013): "para que haja idiorritmia - ou sonho idiorrítmico - é preciso haver: Causa difusa, vaga, incerta, Télos flutuante, fantasia mais do que fé (pp. 88 - 89). Lembremos que para ele há uma "relação consubstancial entre poder e ritmo. O que o poder impõe, antes de tudo, é um ritmo (de todas as coisas: de vida, de tempo, de pensamento, de discurso)" (p. 68). Sendo assim, "a demanda da idiorritmia se faz sempre contra o poder" (idem).

Imaginar a idiorritmia como princípio aglutinante é abrir espaço para a emergência de pequenas frestas onde a política pode emergir, como uma disritmia nos mecanismos de inércia e repetição. Este mesmo ideal parece permear algumas das ideias de Migliorin (2012) acerca dos coletivos:

a manutenção da intensidade que atravessa um coletivo depende da possibilidade de suportar e fomentar a coabitação de velocidades distintas, presenças inconstantes e dedicações não mensuráveis em dinheiro e tempo, uma vez que são as intensidades transindividuais que garantem a força irradiadora do grupo (p. 309).

4 Crendo que "os distúrbios do normal e do regular muitas vezes nos oferecem um maior insight sobre o normal do que o estudo direto" (TURNER, 2008, p. 30), o antropólogo se interessa especialmente pelos momentos de "irrupção pública de tensão" (idem, p. 28), que chama de drama social. Ele o divide em quatro fases: ruptura, crise, ação corretiva e reintegração. Turner oferece teorias que podem servir tanto para uma análise micro ou macropolítica. 
Ora, se a idiorritmia se refere, grosso modo, a uma forma de inserção do sujeito no código social sem nele perder aquilo que lhe é particular, então voltamos às subjetividades e modos de subjetivação. Afinal, da mesma maneira que trabalhar dentro das formas de aglutinação oferecidas pela governamentalidade moderna é se render a possibilidades muito restritas de ação política, mostra-se importante imaginar outros registros de coesão social cuja fluidez dificulte sua captura pelas estruturas. É interessante lembrar que uma das possíveis formas de contra-conduta ao poder pastoral, que Foucault qualifica como cogenético ao biopolítico, era justamente o pertencimento ou criação de grupos à sua margem, que funcionassem como uma "contra-sociedade" (FOUCAULT, 2008).

Desta forma, talvez a ideia do coletivo como sujeito político relevante no contemporâneo esteja menos ligada ao seu modelo tipológico, como grupalidade paralela ao Estado, mas a uma práxis incessante e reflexiva que permeia ativamente as formas do estar junto, responsável por manter seus integrantes em constante tensão dissensual.

\subsection{A coletividade do Opavivará!}

No caso do Opavivará! a aglutinação enquanto coletivo ultrapassa seus mecanismos internos de coesão e organização, transbordando para a poética dos trabalhos que produzem. Eles invariavelmente estão engajados na formação de outros corpos coletivos e efêmeros, reunidos em torno daquilo que seus membros denominam como dispositivos relacionais, na linha das formulações do crítico de arte francês Nicolas Bourriaud (2009). Os atos de cozinhar, comer e beber coletivamente são recorrentes nas ações do Opavivará!. Nestas ações habituais rapidamente localizamos algumas das dimensões performáticas e rituais da vida em comunidade, em que a experiência corpórea do prazer individual é colocada para esbarrar com a alteridade. A alimentação é uma das atividades cotidianas frequentemente arrastadas para dentro da poética do coletivo e emerge como dispositivo que incita relações.

Neste eixo poético podemos citar trabalhos como Cozinha Coletiva $(2007,2016)$ e Opavivará! ao Vivo (2012), em que pessoas são postas para cozinhar e comer com os membros do coletivo, seja em espaços públicos ou no branco asséptico de galerias. O coletivo inclusive conta que teve diversos problemas com instituições biopolíticas tais como a vigilância sanitária, que procurou cerceá-los algumas vezes nas ações em que a comida poderia estar contaminada e fazer mal aos participadores. Em Opavivará! ao Vivo este impasse foi resolvido de forma tática ${ }^{5}$. Mas experimentar os trabalhos do coletivo é correr o risco de contaminação, de estar entre outros e ser afetado, romper o registro das divisões que repartem e disciplinam: os trabalhos produzem formas de estar junto com o outro. Comer é também contaminar-se.

Em Parabéns para você, mercadão de Madureira (2010) somos convidados a performar uma insólita comemoração de aniversário, com todas as suas convenções rituais. Como não poderia faltar, nos são oferecidos pedaços de bolo, mas neles há

5 Na ação Opavivará! ao vivo (2013) a vigilância sanitária foi acionada por conta de uma reportagem produzida sobre o trabalho veiculada em um noticiário televisivo. Mas proibido de continuar a ação, o coletivo Opavivará! ameaçou veicular no mesmo noticiário uma errata, anunciando censura por parte da prefeitura. Foi desta forma que o coletivo conseguiu permissão para atuar na praça. 
retratos dos lojistas do famoso mercado popular impressas. Assim, o ritual de aniversário se transforma em uma comilança antropofágica, onde nos alimentamos coletivamente de pedaços dos corpos destes lojistas. Ao lançar mão de uma técnica totalmente exótica ao meio da arte, aplicada a um suporte efêmero e perecível como o próprio corpo, o trabalho ri da sacralidade da figura do corpo na História da Arte e comenta os regimes de reprodução e circulação das imagens.

O desvio poético que põe em jogo as múltiplas formas pelas quais deglutimos as imagens também permeia trabalhos como Colorbar (2011), desta vez de forma mais decantada. Nele nos servimos de bebidas alcoólicas de diversas cores, texturas e sabores, até percebermos que a experiência do corpo nos dá sinais de tontura e da vertigem dos excessos. A cor aqui aparece como matéria palpável, passível de engendrar sensações que embaralham a visualidade e produzem desorientação: dela nos alimentamos e ela nos embriaga. A arte é justamente aquilo que coloca o corpo em deriva, e aqui a redistribuição na ordem do sensível emerge radicalmente em sua literalidade, em um comentário sutil à condição eminentemente desnorteadora do fato artístico. Afixados à parede, os suportes transparentes usados para os líquidos coloridos se tornam uma espécie de pintura concretista nômade, que muda à medida que os usuários os consomem.

Por outro lado, é impossível ignorar que, a despeito das críticas institucionais propaladas pelo coletivo e de sua saída dos muros da galeria em direção à cidade, uma vez inserido no circuito oficial da arte contemporânea, o Opavivará! está ancorado a processos sociais que escapam das possibilidades políticas internas aos trabalhos. Podemos, por exemplo, estabelecer relações entre os trabalhos do coletivo e os processos de gentrificação engendrados pela arte a partir da ação Pulacerca (2009). Concebida quando a Praça Tiradentes ${ }^{6}$ ainda era gradeada, esta ação consistiu da instalação de escadas que permitiam pular seu cercado, produzindo uma outra possibilidade de circulação naquele local.

Segundo os membros do coletivo, este trabalho teria contribuído para a posterior demolição das grades da praça, uma vez que haveria formas "invisíveis" de controlar os fluxos pelo espaço urbano. Mas que poder seria esse que, mesmo com a demolição das barreiras físicas e disciplinares ainda se mantém ativo na gestão dos fluxos e dos corpos na cidade? Aqui convém recordar que a região da Praça Tiradentes vem sofrendo um processo de gentrificação ${ }^{7}$ especialmente impulsionado pelo plano de Revitalização da Praça Tiradentes, iniciado pela Prefeitura em 2001 no âmbito do Projeto Munumenta. Além da demolição das grades da praça, ele compreende a gradual instalação de agentes da Indústria Criativa na região e a Gentil Carioca, galeria que representa o coletivo Opavivará!, está implicada.

Tratam-se de mecanismos de captura, que certamente incidem sobre suas poéticas, mas que não aniquilam por completo sua potência dissensual. O coletivo busca estar ciente destas ambiguidades e responde a críticas desta natureza afirmando pra-

6 Praça localizada no Centro da cidade do Rio de Janeiro.

7 Carmen Beatriz Silveira (2006) detalha o processo de gentrificação da Praça Tiradentes e de suas imediações. Ele ainda está em curso, mas dentre seus marcos importantes podemos citar a interdição de parte da Rua do Lavradio (rua que liga a Lapa à Praça Tiradentes, ambos na região central do Rio de Janeiro) para carros. Esta porção, próxima à Praça Tiradentes, se tornou um polo atrativo para turistas e bares caros, onde a população local dificilmente pode consumir. Mais recentemente vimos a reforma de equipamentos culturais já existentes na região, tais como os teatros João Caetano e Carlos Gomes, e o Centro Municipal de Arte Hélio Oiticica. Posteriormente foram instalados o Studio-X, o Centro Carioca de Design e o CRAB (Centro Sebrae de Referência do Artesanato Brasileiro). Recentemente a Gentil Carioca, galeria de arte que representa o coletivo Opavivará!, foi ampliada para um sobrado de três andares na região. 
ticar a "promiscuidade institucional". Ou seja, ele procura se situar no interior de uma galeria e produzir a crítica de dentro dela, evita deixar de ocupar espaços e instituições por haver algum ponto passível de crítica, não se furta de se utilizar de editais etc. Talvez esta atitude integre o nomadismo ideológico exercitado pelo coletivo. Ou se alinhe enquanto delito tático, como "movimento dentro do campo do inimigo", que joga no terreno "que lhe é imposto tal como o organiza a lei de uma força estranha" (CERTEAU, 1994, p. 100).

Resta refletir se os trabalhos do coletivo se organizam enquanto uma força estranha dentro dos circuitos que lhe compreendem ou se foram totalmente tragados e incorporados, servindo como força motriz para os processos de gentrificação. Em todo o caso, o Opavivará! procura evitar ao máximo a noção de resistência: "a realidade é irresistível!", afirma um de seus membros.

Há também uma série de obras do coletivo questionáveis do ponto de vista de uma economia simbólica, que dialogam de forma muito próxima com aquilo que se convencionou chamar de "cultura popular". Estes trabalhos fagocitam para dentro da poética do Opavivará! uma estética oriunda de alteridades ou minorias sociais, de acordo com um regime de franca influência antropofágica. Dentre eles poderíamos citar Eu amo camelô (2009), em que vendedores de mate de praia, proibidos de exercerem seu ofício pelo então prefeito Eduardo Paes, são retratados em cartões postais. Ou Transnômades (2016), em que os carros a tração humana, tão comuns nas grandes cidades, são acrescidos de funções agregadoras ou coletivas, convidando espectadores a levá-los pela cidade, em uma carreata nômade. Algumas referências indígenas também povoam alguns trabalhos esparsos do coletivo, tais como Self Service Pajé (2015).

Ainda que no primeiro caso o dinheiro seja repassado para os vendedores de mate e que, no segundo, o coletivo tenha estabelecido uma proximidade duradoura com as pessoas cujo ofício é carregar estes carrinhos diariamente, trata-se de um procedimento de ressignificação muito delicado. Pois no âmbito das operações de deslocamento que arrastam partes do mundo para os circuitos da arte não é fácil delimitar as fronteiras entre os trabalhos que funcionam no registro da mera apropriação e da exotização de uma alteridade, e aqueles que operam de maneira antropofágica. Suely Rolnik (2006) procura estabelecer algo semelhante em sua Geopolítica da Cafetinagem, diferenciando a antropofagia de uma "baixa antropofagia":

a Antropofagia em si mesma é apenas uma forma de subjetivação, de fato distinta da política identitária. No entanto, isto não garante nada pois esta forma pode ser investida segundo diferentes éticas, das mais críticas às mais reacionárias, o que Oswald de Andrade apontava, designando estas últimas de 'baixa antropofagia' (...). Esta diferença está na estratégia de criação de territórios e, implicitamente, na política de relação com o outro: para que este processo se oriente por uma ética de afirmação da vida é necessário construir terrenos com base nas urgências indicadas pelas sensações - ou seja, os sinais da presença do outro em nosso corpo vibrátil. É em torno da expressão destes sinais e de sua reverberação nas subjetividades que respiram o mesmo ar do tempo que vão se abrindo possíveis na existência individual e coletiva (p. 10).

\section{Conclusão}

Notamos que a arte, ao engendrar processos de singularização no seio da urbanidade, pode significar uma forma política extremamente relevante na contempora- 
neidade. À contrapelo das políticas urbanas, sempre interessadas em resolver problemas, a arte pode produzir fissuras na ordem do sensível. Assim ela atua sensivelmente nos próprios corpos dos sujeitos, de modo a fazer solapar os processos de individualização e massificação que caracterizam a experiência urbana contemporânea. Surge aí um aspecto micropolítico suscitado pelo regime estético da arte: a relação entre espectador e obra envolve a produção ativa de um sujeito, como um processo de singularização que resiste à possibilidade de sujeição e controle sobre os corpos. Neste sentido, em termos foucaultianos, a arte se impõe como um trabalho sobre si que engendra modos de subjetivação.

Os coletivos parecem condensar alguns dos importantes elementos para uma ação política, uma vez que se configuram como grupos eminentemente dissensuais, interessados em tencionar as formas de grupalidade identitárias. Desta forma, as relações que o Opavivará! estabelece com a cidade extravasam a pura dimensão palpável do tecido urbano. Isto porque antes de tudo o espaço público é - ou deveria ser - aquele da sociabilidade, onde a experiência com a alteridade toma forma. Mesmo quando o coletivo concebe trabalhos para feiras, galerias ou museus de arte, a esfera pública inescapavelmente participa, seja na forma das relações estabelecidas entre as pessoas que os experimentam ou como incorporação de memórias sociais coletivas e afetivas. $O$ impulso de sair do espaço da galeria parece não se tratar, neste caso, de uma mera crítica institucional vazia, que vê o poder localizado em apenas um foco, mas habita o âmago da poética do coletivo. Assim, o âmbito social do espaço público pode ser mapeado em diversos níveis dos trabalhos, a começar por sua própria constituição enquanto coletivo.

Por outro lado, a cada vez que a arte se aproxima da vida como campo politizado, se imbricando aos movimentos sociais, cabe aos seus agentes pensar de que forma estão envolvidos em apagamentos de memória, invisibilizações, processos de gentrificação, apropriação cultural, violência simbólica etc. Portanto, se é verdade que o contemporâneo tenha assistido a uma falência do devir autônomo das artes plásticas, então este assunto complexo e intrinsecamente político se mostra da maior importância.

\section{Referências}

BARTHES, R. Aula: aula inaugural da Cadeira de Semiologia Literária do Colégio de França. São Paulo: Cultrix, 2013.

Como viver junto: simulações romanescas de alguns espaços cotidianos. São Paulo: Martins Fontes, 2013.

BENJAMIN, W. Obras Escolhidas III: Charles Baudelaire - Um lírico no auge do Capitalismo. São Paulo: Editora Brasiliense, 1991.

A modernidade e os modernos. Rio de Janeiro: Tempo Brasileiro, 2000.

BEY, H. Taz: Zona Autônoma Temporária. São Paulo: Conrad, 2004. 
BIDOU-ZACHARIASEN, C. (org.). De volta à cidade: dos processos de gentrificação às políticas de "revitalização" dos centros urbanos. São Paulo: Annablume, 2006.

BOURRIAUD, N. Estética Relacional. São Paulo: Martins Fontes, 2009.

CERTEAU, M. A invenção do cotidiano I: as artes do fazer. Petrópolis: Vozes, 1994. FOUCAULT, M. Microfísica do Poder. Rio de Janeiro: Graal, 1989.

O sujeito e o poder. In: DREYFUS, Hubert \& RABINOW, Paul. Michel Foucault, Uma trajetória filosófica: para além do estruturalismo e da hermenêutica. Rio de Janeiro: Forense Universitária, 1995.

Em defesa da sociedade: Curso dado no Collège de France (1975-1976). São Paulo: Martins Fontes, 1999.

Segurança, território, população: Curso dado no Collège de France (19771978). São Paulo: Martins Fontes, 2008.

Vigiar e punir: nascimento da prisão. Petrópolis: Vozes, 2009.

GUATTARI, F. Caosmose: um novo paradigma estético. Rio de Janeiro: Editora 34, 1992.

HARDT, M. \& NEGRI, A. Multidão: Guerra e democracia na era do Império. Rio de Janeiro: Record, 2005.

MIGLIORIN, C. O que é um coletivo? In: BRASIL, André. Teia 2002-2012. Belo Horizonte: Teia, 2012.

PÉLBART, P. P. Elementos para uma cartografia da grupalidade. In: SAADI, F. \& GARCIA, S. (Org.). Próximo ato: questões da teatralidade contemporânea. São Paulo: Itaú Cultural, 2008.

RANCIĖRE, J. O Desentendimento: política e filosofia. São Paulo: Ed. 34, 1996.

A partilha do sensível. São Paulo: Editora 34, 2009.

REZENDE, R. \& SCOVINO, F. Coletivos. Rio de Janeiro: Editora Circuito, 2010.

ROLNIK, S. "Geopolítica da cafetinagem". In: SCHÜLER, Fernando \& AXT, Gunter (orgs.). Brasil contemporâneo. Crônicas de um país incógnito. Porto Alegre: Artes e ofícios, 2006.

SILVEIRA, C. B. "Projetos urbanos culturais na cidade do Rio de Janeiro". In: JEUDY, J. P. \& JACQUES, P. B. (orgs.). Corpos e cenários urbanos. Salvador: EDUFBA.

TURNER, V. Dramas, campos e metáforas: ação simbólica na sociedade humana. Niteroi: EdUFF, 2008. 